\title{
Preservative of Essential Oil Blends: Control of Clostridium perfringens Type a in Mortadella
}

\author{
Heloísa Helena de Abreu Martins ${ }^{1}$ \\ https://orcid.org/0000-0002-8071-6644
}

Luara Aparecida Simões ${ }^{2}$

https://orcid.org/0000-0003-4182-5175

Silas Rodrigo Isidoro ${ }^{3}$

https://orcid.org/0000-0002-7285-3673

\author{
João Paulo Alcântara ${ }^{3}$ \\ https://orcid.org/0000-0003-0315-8447 \\ Eduardo Mendes Ramos ${ }^{3}$ \\ https://orcid.org/0000-0002-8240-8151
}

\author{
Roberta Hilsdorf Piccoli ${ }^{*}$ \\ https://orcid.org/0000-0003-2334-9400
}

\section{Sabrina de Souza Nascimento ${ }^{3}$ \\ https://orcid.org/0000-0002-5387-2510}

\begin{abstract}
${ }^{1}$ Federal Institute of Education, Science and Technology Baiano, Department of Agroindustry, Itaberaba, Bahia, Brazil; ${ }^{2}$ Federal University of Lavras, Department of Biology, Lavras, Minas Gerais, Brazil; ${ }^{3}$ Federal University of Lavras, Department of Food Science, Lavras, Minas Gerais, Brazil.
\end{abstract}

Editor-in-Chief: Paulo Vitor Farago

Associate Editor: Jane Manfron Budel

Received: 2020.02.24; Accepted: 2020.12.18.

*Correspondence: rhpiccoli@ufla.br; Tel.: +55-35-38291656 (R.H.P.).

\section{HIGHLIGHTS}

- The blends of essential oils were effective against vegetative cells of $C$. perfringens.

- The blends of essential oils were antioxidants in the meat product.

- Essential oils have a preservative action in mortadella.

Abstract: The aim of this study was to evaluate the antimicrobial effect of the essential oils of cinnamon, cardamom, clove, oregano, and thyme and their synergism on vegetative cells and endospores of Clostridium perfringens type A inoculated in meat sausage (mortadella), as well as the influence of blends on the color, and lipid oxidation through the determination of thiobarbituric acid reactive substances (TBARS index). The anticlostridial action of the oil blends was established. The two added oil blends (Treat. 1: oregano, clove, and thyme; Treat. 2: oregano, clove, and cinnamon) in combination with reduced nitrite content (75 ppm) promoted a lower growth of $C$. perfringens in mortadella stored at $15{ }^{\circ} \mathrm{C}$ for 21 days in comparison to treatments containing only $75 \mathrm{ppm}$ of nitrite. The essential oil blends showed antioxidant action and did not alter food color, thus possessing potential application as a preservative for the meat products industry.

Keywords: endospores; residual nitrite; natural antimicrobial; antioxidant activity.

\section{INTRODUCTION}

Clostridium perfringens is a bacterium commonly found in several environments such as soil, water, plants, the intestinal tracts of animals and humans, as well as in food processing environments [1]. It can produce 16 types of toxins classified as five toxin types (A, B, C, D and E) based on the enterotoxin production 
and four types of extracellular toxins ( $\alpha, \beta, \varepsilon$, and ।) [2]. C. perfringens Type A produces the toxin called $C$. perfringens enterotoxin (CPE), one of the most common causes of food poisoning in the USA, with about 1 million cases per year [3]. In most strains of $C$. perfringens capable of causing food poisoning, the cep gene that encodes to CPE enterotoxin is in the bacterial chromosome. These strains are highly adapted to food transmission due partly to the high resistance of their spores to heat treatment, chemical preservatives, and low temperature [2]. Because it is a fastidious microorganism, it needs a growth medium rich in nutrients, thus it is commonly associated with food-borne outbreaks related to cured cooked meat sausages, since these meat products are a source of amino acids and other nutrients. Furthermore, $C$. perfringens can grow in the presence of high salt concentration (4-6\%) and $300 \mathrm{ppm}$ of sodium nitrite, a curing agent and preservative often used in this product type [4].

Nitrite is the key ingredient in the curing process of cooked meat sausages, and is responsible for the development of the pink coloration of the finished product; it also has antioxidant and bacteriostatic effects [5]. However, nitrite in meat ( $\mathrm{pH}$ between 5.5 and 6.0) is reduced to nitrous acid, resulting from the hydration of the nitrite oxide produced by the reduction of nitrite, which enables it to react with amines in cured meat products for the formation of $\mathrm{N}$ - nitrous compounds, especially nitrosamines. The latter have toxic, mutagenic, neurotoxic, nephrotoxic and carcinogenic effects [6], and are also correlated to health problems with brain tumors and leukemia [7].

Although nitrite has several undesirable characteristics, few alternatives are suggested to promote its elimination or reduction in cured meat sausages. Thus, alternative preservatives to nitrite have been studied. Among the natural additives, essential oils (EOs) have been highlighted and widely accepted by consumers, besides being generally recognized as safe (GRAS). EOs are complex blends that can contain between 20 and 60 different components occurring in different concentrations. Usually one of them is the major compound, representing $80 \%$ or more of the EO composition, in combination with others in lower contents [8]. Several action mechanisms of EOs on bacteria are hypothesized, such as increase in permeability and alteration of the fatty acid profile of the plasma membrane, alteration of the proton-motive force, anti-quorum sensing activity, effect on membrane proteins, action on ATP and ATPase, effect on cytoplasmic proteins and cytoplasmic coagulation [9].

Although several studies have shown that EOs retain their antimicrobial activity when added to food matrices, evaluations typically involve only one EO and their concentrations are generally high [10-12]. An alternative to this problem is the study of the antimicrobial activity of several EOs in combinations with each other and / or with other conservation technologies [13]. Some recent studies have been reported in this regard.

A study [14] evaluated the effect of nutmeg essential oil (NEO) on the oxidative and microbial stability of cooked sausages during refrigerated storage and concluded that a maximum amount of $20 \mathrm{ppm}$ of NEO can be applied to extend shelf life. In a combination of preservatives, Smaoui at al [15] evaluated the combination of Mentha piperita EO with a commercial bacteriocin, and observed an interesting biopreservative effect in minced raw beef during cold storage. The addition of the $\mathrm{EO}$ combined with bacteriocin delayed the proliferation of deteriorating microorganisms, limited the oxidation of lipids and extended the shelf-life in raw beef. Another study by Stojanović-Radic and coauthors [16] investigated the effect of the basil and rosemary EOs as well as their combination on the growth of Salmonella enterica serovar Enteritidis (Salmonella Enteritidis) in chicken meat, together with their potential protective spoilage at the two storage temperatures, and obtained positive results suggesting the use of EOs to extend shelf life and prevent pathogen contamination in chicken meat. Šojić and coauthors [17] in a very complete study, evaluated the effect of coriander essential oil (CEO) on microbial growth in cooked pork sausages produced with different levels of sodium nitrite. Both data from physical-chemical analyzes (color, $\mathrm{pH}$, TBARS) and microbiological analyzes suggest potential use of CEO in the processing of cooked pork sausages, contributing to increased quality and shelf-life. Furthermore, Radünz and coauthors [18] evaluated the thyme EO in vitro and in situ in hamburger-like meat products. The encapsulated EO showed antioxidant and antimicrobial activity against pathogenic microorganisms (Staphylococcus aureus, Escherichia coli, Listeria monocytogenes and Salmonella Typhimurium) tested in vitro and against Escherichia coli in situ, showing potential for application as a natural preservative in food.

As EOs have antimicrobial action both on deteriorating and pathogenic microorganisms, antioxidant activity and also add flavor to the product, they are of great interest in the development of additives for meat and meat products. Thus, the aim of this study was to evaluate the antimicrobial activity of EO combinations on vegetative cells and endospore of $C$. perfringens Type $A$ and the preservative and antioxidant action of these combinations in mortadella. This study is important because it shows the action of EOs against 
endospore-forming bacteria, and works on the hypothesis that the use of EOs can reduce the amount of nitrite in a meat product, keeping this product safe for the consumer and making it the healthiest.

\section{MATERIAL AND METHODS}

\section{Essential oils}

Essential oils of Origanum vulgare (oregano); Thymus vulgaris (thyme); Cinnamomum zeylanicum (cinnamon); Syzygium aromaticum (clove) and Elettaria cardamomum (true cardamom) were used, purchased from FERQUIMA Indústria e Comércio Ltda, Vargem Grande, São Paulo, Brazil. The constituents of essential oils were characterized by Gas Chromatography - Mass Spectrometry (GC-MS) (Shimadzu, GCMS-QP2010 Plus), except cardamom essential oil (industry information). The main chemical constituents are presented in Supplementary Material 1.

\section{Microorganism, standardization and maintenance of the inoculum}

Clostridium perfringens Type A, INCQS 00130 (ATCC 13124) used in this study was provided by the National Institute of Quality Control in Health (INCQS) of the Oswaldo Cruz Foundation (FIOCRUZ), Rio de Janeiro, RJ, Brazil.

Inoculum maintenance was done according to Dias and coauthors [13]. Inoculum standardization (10 ${ }^{7}$ $\mathrm{CFU} / \mathrm{mL}$ ) was performed with a growth curve $(\mathrm{OD} 600 \mathrm{~nm})$ and counting on $\mathrm{BHI}$ agar plates, with overlay, supplemented with $0.5 \%$ glucose and incubated at $37^{\circ} \mathrm{C}$ for $24 \mathrm{~h}$.

The endospores were obtained after strain reactivation, standardization, inoculation on sporulation medium (meat extract: $3 \mathrm{~g}$, tryptone: $5 \mathrm{~g}$, starch: $1 \mathrm{~g}$, manganese sulfate: $10 \mathrm{mg}$, distilled water: $1000 \mathrm{~mL}$ ) and incubation at $37^{\circ} \mathrm{C}$ for 6 days. The culture containing the endospores was subjected to thermal shock $\left(75^{\circ} \mathrm{C}\right.$ for $15 \mathrm{~min} / 0^{\circ} \mathrm{C}$ for $\left.15 \mathrm{~min}\right)$ and the presence of endospores was confirmed by observation under an optical microscope using the Wirtz-Conklin staining technique. The culture was centrifuged $(10,000 \times \mathrm{g} / 5$ min.) and the endospores were stored in freezing medium. Endospore inoculum was standardized at $10^{6}$ $\mathrm{CFU} / \mathrm{mL}$ by plating on $\mathrm{BHI}$ agar plus $0.5 \%$ glucose and incubation at $37^{\circ} \mathrm{C}$ for $48 \mathrm{hr}$.

All culture media used were from the Himedia, Mumbai, India and reagents were from VETEC, SigmaAldrich Brazil, Duque de Caxias, Brazil.

\section{Minimum bactericidal (MBC) and sporicidal concentration (MSC) of essential oils}

The determination of the minimum bactericidal (MBC) and sporicidal concentrations (MSC) was performed using the $\mathrm{BHI}$ broth supplemented with $0.5 \%$ glucose added with $0.5 \%$ Tween $(\mathrm{BHI}+\mathrm{G}+\mathrm{T})$. The essential oil concentrations evaluated ranged from 0 to $8 \%(\mathrm{v} / \mathrm{v})$, varying with fractions of $0.25 \%$. The essential oils were diluted in BHI broth containing Tween $80(\mathrm{v} / \mathrm{v})$ in the desired concentrations. Aliquots of $20 \mu \mathrm{L}$ of the standardized culture of vegetative cells or spore suspension were transferred to tubes containing $5 \mathrm{~mL}$ of $\mathrm{BHI}+\mathrm{G}+\mathrm{EO}$ and incubated at $37^{\circ} \mathrm{C} / 24 \mathrm{~h}$ under anaerobic conditions obtained with the addition of mineral oil. After this period, pour plate technique with an overlay was used by adding $1 \mathrm{~mL}$ of the culture plated in $\mathrm{BHI}+$ agar+G and incubated at $37^{\circ} \mathrm{C} / 24 \mathrm{~h}$. MBC and MSC were considered as the lowest concentration of each oil where there was no visible growth on the plates. Experiments were performed in triplicate with three repetitions.

\section{Determination of antimicrobial activity of essential oil combinations}

The five essential oils isolated were selected for three-oil combination assessments. The sets of three essential oils were formed by mixing the five oils randomly until a reasonable number of combinations to be evaluated were obtained. Table 1 shows the different ratios relative to the MBC and MSC of each oil used in the combinations. 
Table 1. Matrix of the simplex centroid mixture design of essential oils concentration employed for in vitro bactericidal and sporicidal activity.

\begin{tabular}{ccccc}
\hline Run & \multicolumn{3}{c}{ Independent variables * $^{*}$} \\
\cline { 2 - 4 } & Essential oil 1 & Essential oil 2 & Essential oil 3 \\
\hline 1 & 100 & - & - \\
2 & - & - & - \\
4 & - & 50 & - \\
5 & 50 & - & 50 \\
6 & - & 50 & 50 \\
7 & 67 & 17 & 17 \\
8 & 17 & 67 & 17 \\
9 & 17 & 17 & 67 \\
10 & 33 & 33 & 33
\end{tabular}

*100 (MBC and MSB); 50 (0.5MBC; and 0.5MSC); 67 (0.67MBC; and 0.67MSC); 33 (0.33MBC; and 0.33MSC); 17 (0.17MBC; and 0.17MSC).

\section{Manufacture of meat sausage: mortadella}

The mortadella was composed of beef, $56.5 \%$; pork backfat, $14.5 \%$; water/ice, $20 \%$; cassava starch, $5 \%$; salt, 2\%; polyphosphate, 0.5\%; antioxidant Fixamax®, 1\%; and nitrite $75 \mathrm{ppm}$ (sodium nitrite), for all treatments., All additives were kindly provided by IBRAC® (Brazil). Two combinations of essential oils were used: Treat 1 containing $0.165 ; 0.066$; and $0.165 \%$ of oregano, clove, and thyme, respectively; and Treat 2 containing $0.165 ; 0.066$; and $0.066 \%$ of oregano, clove, and cinnamon, respectively.

The mortadella was shredded into a cutter (Sire, Filizola S.A., Brazil) and the batters were stuffed into 65-67 mm diameter synthetic bags (polyamide) (Viskase ${ }^{\circledR}$, Brazil) in order to obtain mortadella samples of about $450 \mathrm{~g}$. Cooking was carried out by immersion in a water bath until the internal temperature reached 70-72 ${ }^{\circ} \mathrm{C}$ (measured with thermocouple).

The samples were then inoculated with $10^{7} \mathrm{CFU} / \mathrm{g}$ of $C$. perfringens vegetative cells, homogenized in Stomacher (Metroterm ${ }^{\circledR}$, Brazil) (490 strokes/2 min) at room temperature, and separated in $10 \mathrm{~g}$ portions in plastic (Unipac Darlon, Brazil, $50 \mu \mathrm{m}$ thickness) vacuum-sealed packages and stored at $15^{\circ} \mathrm{C} \pm 1{ }^{\circ} \mathrm{C}$. Mortadella destined for physical and chemical analyses (without microorganism) were stored at $4.4^{\circ} \mathrm{C}$. The mortadella were analyzed after $0 ; 7$; and 21 days of storage. The experiment was performed in three replicates.

\section{Enumeration of Clostridium perfringens in mortadella}

The mortadella were homogenized in $90 \mathrm{~mL}$ of $0.1 \%(\mathrm{~m} / \mathrm{v})$ peptone water in Stomacher Metroterm® $(490$ beats $/ \mathrm{min}$ ) for $3 \mathrm{~min}$. Aliquots of $1 \mathrm{~mL}$ of the appropriate dilutions were plated on SPS agar (Sulfite Polymyxin Sulfadiazine) using the plating technique in depth with overlay and incubated at $37^{\circ} \mathrm{C} / 24 \mathrm{~h}$. Analyses were performed in triplicate with three repetitions.

\section{Evaluation of Lipid oxidation (TBASs index) and overall color difference ( $\left.\triangle E^{*}\right)$}

TBARS index analyses were performed according to the methodology described by Raharjo and coauthors [19] with modifications [20].

Evaluation of the objective color of products was carried out using a Konica Minolta® CM-600D portable spectrophotometer colorimeter, following the recommendations for cured products (21). To calculate the color indexes, the illuminant $A$ and the CIELAB color system were established. Overall color difference $\left(\Delta E{ }^{*}\right)$ was calculated using the equation $\left(\Delta E^{*}\right)=\left[\left(L^{*}-L \text { ref }\right)^{2}+\left(a^{*} \text {-aref }\right)^{2}+\left(b^{*} \text {-bref }\right)^{2}\right]^{0,5}$, the reference parameters being those of the control at time 0 .

\section{Statistical analyses}

The essential oils combinations were geared using the Simplex-Centroid Design [22] and showed in Table 1. The results (growth/non-growth) of the different assays of the combinations among essential oils were submitted to principal component analysis (PCA) using Chemoface 1.5 software. Results for antimicrobial action of the oil combinations on $C$. perfringens in mortadella and physical and chemical 
analyses were submitted to analysis of variance (ANOVA), and the averages were compared through the Tukey test at 5\% significance level, using Sisvar software version 5.6.

\section{RESULTS}

\section{Minimal bactericidal (MBC) and sporicidal concentration (MSC) of essential oils and its combinations}

MBC was $0.5 \%$ for oregano and thyme essential oils and $0.2 \%$ for cinnamon, clove, and true cardamom oils. The major components of essential oils used in this study were $80.67 \%$ of eugenol in clove oil, $73.11 \%$ of carvacrol in oregano; $50.89 \%$ of thymol and $24.97 \%$ of p-cyneme in thyme oil, and $84.52 \%$ of Ecinnamaldehyde in cinnamon. Cardamom essential oil showed $41.45 \%$ of $\alpha$-terpineol (data provided by the industry). All these components are known for their antimicrobial and antioxidant activity [23-24].

Based on the MBC, several blends containing three essential oils were prepared with different concentrations (Table 1), in attempting to increase synergy and reduce oil concentrations.

In vitro antimicrobial activity of the different essential oil blends on vegetative cells of C.perfringens is shown in Table 2. The runs 1, 2 and 3 correspond to $100 \%$ of the MBC of the individual oils. Among the blends containing two oils (50: $50 \%$ of their $\mathrm{MBC}$ ) represented by runs 4,5 and 6 and containing $0.1 \%$ clove and $0.25 \%$ oregano; $0.25 \%$ oregano and $0.25 \%$ thyme; $0.25 \%$ thyme and $0.1 \%$ cinnamon; and $0.1 \%$ of true cardamom and $0.1 \%$ of cinnamon were bactericidal.

Table 2. Bactericidal activity in vitro of essential oil blends against vegetative cells of $C$. perfringens type $A$

\begin{tabular}{cccccccc}
\hline \multirow{2}{*}{ Run } & \multicolumn{7}{c}{ Essential oils blends } \\
\cline { 2 - 7 } & Cl:Or:Th & Cl:Or:Car & Cl:Or:Cin & Or:Th:Car & Or:Th:Cin & Th:Car:Cin \\
\hline 1 & + & + & + & + & + & + & + \\
2 & + & + & + & + & + & + \\
3 & + & - & - & - & - & + & + \\
4 & + & + & - & - & + & + \\
5 & + & + & - & - & + & + \\
6 & + & + & - & - & + & + \\
7 & + & + & + & - & + & + \\
8 & + & + & + & + & -
\end{tabular}

(+) bactericidal activity; (-) without bactericidal activity. ${ }^{\star}$ Essential oils - Cl: Clove; Or: Oregano; Car: True Cardamom; Cin: Cinnamon; Th: Thyme.

Among the blends containing three oils, in the several ratios, a majority showed bactericidal activity, suggesting synergistic/additive antimicrobial effect among the essential oils. Among the assays containing clove, oregano and cinnamon, only one containing $0.07 \%$ clove, $0.17 \%$ oregano and $0.07 \%$ cinnamon (run 10) was bactericidal. However, the tests containing oregano, thyme and true cardamom oils did not show antimicrobial activity. Thyme, true cardamom and cinnamon were bactericidal in the assays where the ratio of thyme oil was $17 \%$ of the MBC (run 8 and 9). At higher concentrations, there was no bactericidal activity, showing a probable antagonism between thyme oil and the others. Observing the PCA (Figure 1A) of the essential oils combinations, oregano and clove oils are highlighted with the greatest contribution to the bactericidal effect of the different tested combinations. These results were similar to those obtained by Dias and coauthors [13], who found that blends containing the highest ratios of oregano essential oil were more effective against $C$. perfringens type $A$. The phenolic constituents present in essential oils alter the permeability and break the cell membrane leading to the inhibition of functional properties and leakage of the internal content, leading to cell death [25]. True cardamom and thyme oils showed lower intensity effects on vegetative cells of $C$. perfringens.

The antimicrobial action of essential oils on $C$. perfringens endospores was not as effective. The sporicidal activity for blends of two oils was restricted to combinations containing true cardamom (4\% thyme 
and $4 \%$ true cardamom, $4 \%$ clove and $4 \%$ true cardamom, and $3.65 \%$ oregano and $4 \%$ true cardamom) (run 4, 5 and 6). For blends containing three oils, only two combinations were sporicidal: oregano $4.86 \%$, thyme $1.36 \%$, and true cardamom $1.36 \%$; and clove $1.36 \%$, oregano $4.86 \%$, and true cardamom $1.36 \%$. The important presence of true cardamom oil in blends with sporicidal actions is evidenced in the PCA (Figure 1B). Besides the essential oil of true cardamom, clove and oregano contributed to sporicidal activity of blends. The activity of thyme and cinnamon essential oils was less expressive. Although some blends showed sporicidal activity, synergism cannot be affirmed, since the combination of essential oils did not act on the endospores in most of the tests. The difference between MBC and MSC can be explained through the endospore structure of $C$. perfringens, since these have high resistance to several environmental stressors [26].
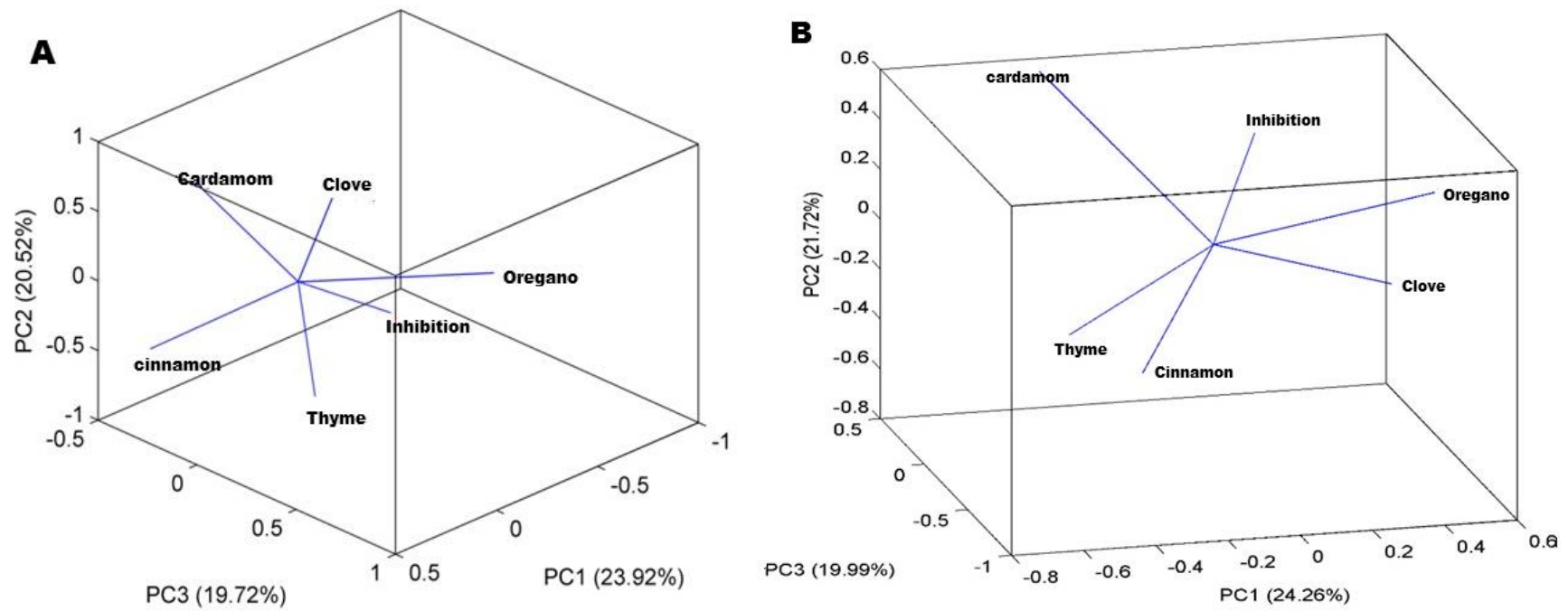

Figure 1. Weights of Principal Component Analysis (PCA) inhibition of C.perfringens type $A(A)$ vegetative cells and $(B)$ endospore from different combinations of oregano, thyme, cloves, cardamom, and cinnamon essential oils.

\section{Antimicrobial activity of essential oils on C. perfringens in mortadella}

Two blends with bactericidal action were added to the mortadella. The sets were defined by pre-tests (data not shown) with the objective of promoting a pleasant aroma and reducing the sensory impact when applied to the meat product; Treat. 1 containing $0.17,0.07$, and $0.17 \%$ of oregano, clove, and thyme, respectively; and Treat. 2 containing $0.17,0.07$, and $0.07 \%$ of oregano, clove, and cinnamon, respectively.

Growth of $C$. perfringens on mortadella plus nitrite $(75 \mathrm{ppm})$ and different combinations of essential oils, maintained at $15^{\circ} \mathrm{C}$, was followed up for 21 days. The vegetative cell count was not significantly affected $(P>0.05)$ during storage time. However, there was a significant difference $(P<0.05)$ among treatments, with a decrease in the CFU/g count in treatments containing essential oils (Table 3 ) in relation to the control.

Table 3. Vegetative cells of Clostridium perfringens (Log UFC/g) in mortadella added with $75 \mathrm{ppm}$ of nitrite and essential oil blends, stored at $15^{\circ} \mathrm{C}$ for 21 days.

\begin{tabular}{cc}
\hline Treatments & Log CFU/g \\
\hline CONTROL & $6.07^{\mathrm{a}}$ \\
TREAT. 1 & $5.59^{\mathrm{b}}$ \\
TREAT. 2 & $4.66^{\mathrm{b}}$
\end{tabular}

Control: $75 \mathrm{ppm}$ of nitrite; TREAT 1: $75 \mathrm{ppm}$ of nitrite + essential oils of oregano $(0.17 \%)$, clove $(0.07 \%)$ and thyme (0.17\%); TREAT 2: $75 \mathrm{ppm}$ of nitrite + essential oils of oregano $(0.17 \%)$, clove $(0.07 \%)$ and cinammon $(0.07 \%)$. Averages followed by different letters in the same column differ among themselves by Tukey test at $5 \%$ probability.

Nitrite at the concentration of $75 \mathrm{ppm}$ (control), without the addition of essential oils, did not inhibit the growth of $C$. perfringens, showing the highest number of CFU/g (6.07 Log CFU/g) in this treatment (control) during storage. Oliveira and coauthors [10] worked with the same strain used in this study and observed that an addition of $200 \mathrm{ppm}$ of nitrite in the formulation of mortadella, a higher concentration than that used as control in this study, reduced 3 cycles log the population of $C$. perfringens on mortadella. 
The blend of oregano, clove and cinnamon oils showed the highest antimicrobial activity, with a reduction of $1.41 \mathrm{Log} C F U / g$ in relation to the control. Although the elimination of $C$. perfringens did not occur, the results suggest the possibility of using essential oils for the control of this microorganism.

Both essential oil blends reduced the growth of $C$. perfringens in the mortadella, however, they were not able to completely inhibit the bacterial growth. Studies with vacuum-packed ground pork showed that oregano essential oil acted in synergism with sodium nitrite (50-100 ppm) inhibited the germination of endospores and growth of $C$. botulinum (type A, B and E) [27]. The synergism between the essential oil of Satureja montana and sodium nitrite, leading to growth inhibition of $C$. perfringens inoculated in mortadella, was also observed by Oliveira and coauthors [10].

In general, the efficiency of several natural antimicrobial agents can probably be reduced by certain food components (water, lipids, carbohydrates, and proteins) [28], since the essential oils appear to be stable and maintain their antimicrobial activity even after being subjected to temperatures of $100{ }^{\circ} \mathrm{C}$ [29], and that high levels of proteins and/or lipids in food matrices seem to protect microorganisms from the action of essential oils [30]. On the other hand, this study used an inoculum of $10^{7} \mathrm{CFU} / \mathrm{g}$, aiming at better detection in cell counts. However, it is known that initial contamination by $C$. perfringens is generally low and the infectious dose is $10^{6} \mathrm{CFU} / \mathrm{g}$ [2].

\section{Influence of essential oils on lipid oxidation and overall color difference of mortadella}

Essential oils showed antioxidant activity, a result observed by the TBARS Index (Table 4). There was no significant interaction between storage time and treatments; however, treatments and time showed a significant influence on the TBARS index. Rancidity can be detected in values above $0.5 \mathrm{mg} \mathrm{MDA} / \mathrm{kg}$, emphasizing that the highest value obtained after 21 days of storage was close to a safe level regarding rancidity detection.

Table 4. Effect of nitrite and different combinations of essential oils on TBAR levels of mortadella during storage at $4.4^{\circ} \mathrm{C}$ for 21 days

\begin{tabular}{cccc}
\hline Treatments & $(\mathbf{m g ~ M A} / \mathbf{K g})$ & Storage (days) & (mg MA/Kg) \\
\hline CONTROL & $0.72^{\mathrm{a}}$ & 1 & $0.48^{\mathrm{a}}$ \\
TREAT. 1 & $0.39^{\mathrm{b}}$ & 7 & $0.50^{\mathrm{ab}}$ \\
TREAT. 2 & $0.44^{\mathrm{b}}$ & 21 & $0.57^{\mathrm{b}}$ \\
\hline
\end{tabular}

Control: $75 \mathrm{ppm}$ of nitrite; TREAT 1: $75 \mathrm{ppm}$ of nitrite + essential oils of oregano $(0.17 \%)$, clove $(0.07 \%)$ and thyme (0.17\%); TREAT 2: $75 \mathrm{ppm}$ of nitrite + essential oils of oregano $(0.17 \%)$, clove $(0.07 \%)$ and cinammon $(0.07 \%)$. Averages followed by the same letter in the column did not differ among themselves by Tukey test at $5 \%$ probability.

Food color is very important to both consumers and the food industry, being a fundamental parameter used in quality control. This sensory characteristic, although subjective, is also responsible for the induction of the global sensation resulting from other characteristics, such as aroma, flavor and texture of foods. There was significant interaction $(\mathrm{P}<0.05)$ among treatments and storage time of mortadella for overall color difference $\left(\Delta E^{*}\right)$ (Table 5). However, the values between the differences did not reach 3. According to Ramos and Gomide [21] global differences smaller than 3.0 cannot be detected by the human eye.

Table 5. Overall color difference $\left(\Delta E^{*}\right)$ in mortadella added with nitrite and different combinations of essential oils, stored at $4.4^{\circ} \mathrm{C}$ for 21 days.

\begin{tabular}{cccc}
\hline & \multicolumn{3}{c}{ Storage (days) } \\
Treatments & $\mathbf{1}$ & $\mathbf{7}$ & $\mathbf{2 1}$ \\
\hline CONTROL & $0^{\mathrm{aA}}$ & $1.38^{\mathrm{bA}}$ & $1.48^{\mathrm{bA}}$ \\
TREAT. 1 & $1.03^{\mathrm{aB}}$ & $1.30^{\mathrm{bA}}$ & $1.47^{\mathrm{bA}}$ \\
TREAT. 2 & $0.56^{\mathrm{aB}}$ & $1.36^{\mathrm{bA}}$ & $1.68^{\mathrm{cA}}$ \\
\hline
\end{tabular}

Control: $75 \mathrm{ppm}$ of nitrite; TREAT 1: $75 \mathrm{ppm}$ of nitrite + essential oils of oregano $(0.17 \%)$, clove $(0.07 \%)$ and thyme (0.17\%); TREAT 2: $75 \mathrm{ppm}$ of nitrite + essential oils of oregano $(0.17 \%)$, clove $(0.07 \%)$ and cinammon $(0.07 \%)$. Averages followed by the same capital letter in the column, and by the same lower case letter in the line there is no difference between them by the Tukey test at $5 \%$ probability.

The results found in this study show that there is a bactericidal action of essential oils against $C$. perfringens type $A$, which is dependent on the chemical composition of each essential oil. Moreover, the difference between MBC and MSC is observed, the latter being a higher concentration showing that the resistance structure of the $\mathrm{C}$. perfringens endospore prevents the penetration of essential oils into the 
structure and does not cause enough damage to lead to inactivation of the microorganism. Thus, the association with other conservation technologies needs to be assessed.

Overall, it was observed that the combination of essential oils is synergistic. The effect of the combined oils is greater than the isolated EOs. In fact this is very important as it allows the decrease in concentration required for antimicrobial action. In practice, this helps to reduce sensory changes when essential oils are added to foods and ensures that their use is economically viable for the industry.

Finally, the results showed that the essential oils when applied in the nitrite-reduced mortadella decreased the cell count of $C$. perfringens and also showed antioxidant action, which may help to increase the shelf life of meat products and ensure a safe product for the consumer. Furthermore, the use of essential oils did not impact the color of the meat product, which is very important since coloration is the first aspect observed by the consumer.

Although the results are promising, essential oils can cause a change in the flavor of foods. Thus, studies should be developed in an attempt to reduce the sensory impact and allow consumer acceptance.

\section{CONCLUSION}

The blend of oregano, clove and cinnamon oils showed greater activity against vegetative cells of $C$. perfringens Type A;

The essential oil blends reduced the growth of $C$. perfringens in mortadella, showed antioxidant action and did not alter the characteristic food color, thus possessing potential application as a preservative for the meat products industry, proving to be an alternative for partial or total replacement of nitrite.

Funding: This research received no external funding

Acknowledgments: The team thanks the University of Lavras (UFLA), the Coordination of Improvement of Higher Level Personnel (CAPES) for its PhD scholarship, the National Council for Scientific and Technological Development (CNPq) and the Foundation for Research of the State of Minas Gerais (FAPEMIG) for its financial support. This study was financed in part by the Coordenação de Aperfeiçoamento de Pessoal de Nível Superior - Brasil (CAPES) Finance Code 001.

Conflicts of Interest: The authors declare no conflict of interest.

\section{REFERENCES}

1. Bahl H, Dürre P. Clostridia: Biotechnology and Medical application. 1st ed. Weinheim: Wiley-VCH Verlag; 2001. $270 \mathrm{p}$.

2. Uzal FA, Freedman JC, Shrestha A, Theoret JR, Garcia J, Awad MM, et al. Towards an understanding of the role of Clostridium perfringens toxins in human and animal disease. Future Microbiol. 2014 Mar;9(3):361-77.

3. Scallan E, Hoekstra RM, Angulo FJ, Tauxe R V., Widdowson M-A, Roy SL, et al. Foodborne Illness Acquired in the United States-Major Pathogens. Emerg Infect Dis. 2011 Jan;17(1):7-15.

4. Bhunia AK. Foodborne Microbial Pathogens. 1st ed. New York: Springer; 2008. 276 p.

5. Jafari M, Emam-Djomeh Z. Reducing nitrite content in hot dogs by hurdle technology. Food Control. 2007 Dec;18(12):1488-93.

6. Rywotycki R. The effect of selected functional additives and heat treatment on nitrosamine content in pasteurized pork ham. Meat Sci. 2002 Apr;60(4):335-9.

7. McKean-Cowdin R, Pogoda JM, Lijinsky W, Holly EA, Mueller BA, Preston-Martin S. Maternal prenatal exposure to nitrosatable drugs and childhood brain tumours. Int J Epidemiol. 2003 Apr 1;32(2):211-7.

8. Bakkali F, Averbeck S, Averbeck D, Idaomar M. Biological effects of essential oils--a review. Food Chem Toxicol. 2008;46(2):446-75.

9. Nazzaro F, Fratianni F, De Martino L, Coppola R, De Feo V. Effect of essential oils on pathogenic bacteria. Pharmaceuticals (Basel). 2013;6(12):1451-74.

10. Oliveira TLC, Soares RA, Ramos EM, Cardoso MG, Alves E, Piccoli RH. Antimicrobial activity of Satureja montana L. essential oil against Clostridium perfringens type A inoculated in mortadella-type sausages formulated with different levels of sodium nitrite. Int J Food Microbiol. 2011;144(3):546-55.

11. Trajano VN, Lima E O, Travassos AE, Souza EL. Inhibitory effect of the essential oil from Cinnamomum zeylanicum Blume leaves on some food-related bacteria. Ciência e Tecnol Aliment. 2010 Sep;30(3):771-5.

12. Jayasena DD, Jo C. Essential oils as potential antimicrobial agents in meat and meat products: a review. Trends Food Sci Technol. 2013 Dec;34(2):96-108.

13. Dias NAA, Rodrigues LTS, Palhares PC, Ramos EM, Piccoli RH. Antimicrobial activity of essential oils on Clostridium perfringens type A inoculated in mortadella. J Food Saf. 2015 Nov;35(4):466-72.

14. Šojić B, Tomović V, Kocić-Tanackov S, Škaljac S, Ikonić P, Džinić N, Zivkovic N, Jokanovic M, Tasic T, Kravić S. Effect of nutmeg (Myristica fragrans) essential oil on the oxidative and microbial stability of cooked sausage during refrigerated storage. Food Control, 2015 Feb;54(1): 282-6.

15. Smaoui S, Hsouna A. B, Lahmar A, Ennouri K, Mtibaa-Chakchouk A, Sellem I. et al. Bio-preservative effect of the 
essential oil of the endemic Mentha piperita used alone and in combination with BacTN635 in stored minced beef meat. Meat Sci. 2016;117(1):196-204.

16. Stojanović-Radić Z, Pejčić M, Joković N, Jokanović M, Ivić M, Šojić B, et al. Inhibition of Salmonella Enteritidis growth and storage stability in chicken meat treated with basil and rosemary essential oils alone or in combination. Food Control. 2018;90.

17. Šojić B, Pavlić B, Ikonić $P$, Tomović V, Ikonić B, Zeković Z, Kocić-Tanackov S, Jokanović M, Škaljac S, Ivić M. Coriander essential oil as natural food additive improves quality and safety of cooked pork sausages with different nitrite levels. Meat Sci. 2019. Jun;157(1):1-8.

18. Radünz M, Hackbart HCS, Camargo TM, Nunes CFP, Barros FAP, Magro JD, Filho PJS, Gandra EA, Radünz AL, Zavareze ER. Antimicrobial potential of spray drying encapsulated thyme (Thymus vulgaris) essential oil on the conservation of hamburger-like meat products. Int. J. Food Microbiol, 2020 Oct;330(2)108696.

19. Raharjo S, Sofos JN, Schmidt GR. Improved speed, specificity, and limit of determination of an aqueous acid extraction thiobarbituric acid-C18 method for measuring lipid peroxidation in beef. J Agric Food Chem [Internet]. 1992 Nov;40(11):2182-5.

20. Oliveira TLC, Carvalho SM, Soares RA, Andrade MA, Cardoso MDG, Ramos EM, et al. Antioxidant effects of Satureja montana L. essential oil on TBARS and color of mortadella-type sausages formulated with different levels of sodium nitrite. LWT - Food Sci Technol. 2012 Mar;45(2):204-12.

21. Ramos EM, Gomide LAM. Avaliação da qualidade de carnes: fundamentos e metodologias. 1st ed. Editora UFV, editor. Viçosa; $2009.599 \mathrm{p}$.

22. Cornell JA. Experiments with Mixtures. Hoboken, NJ, USA: John Wiley \& Sons, Inc.; 2002.

23. Souza AA, Dias NAA, Piccoli RH, Bertolucci SKV. Composição química e concentração mínima bactericida de dezesseis óleos essenciais sobre Escherichia coli enterotoxigênica. Rev Bras Plantas Med. 2016 Mar;18(1):10512.

24. Hyldgaard M, Mygind T, Meyer RL. Essential oils in food preservation: mode of action, synergies, and interactions with food matrix components. Front Microbiol. 2012;3.

25. Bajpai VK, Baek KH, Kang SC. Control of Salmonella in foods by using essential oils: a review. Food Res Int. 2012 Mar;45(2):722-34.

26. Li J, McClane BA. Further comparison of temperature effects on growth and survival of Clostridium perfringens type A isolates carrying a chromosomal or plasmid-borne enterotoxin gene. Appl Environ Microbiol. 2006 Jul 1;72(7):4561-8.

27. Ismaiel AA, Pierson MD. Effect of sodium nitrite and origanum oil on growth and toxin Production of Clostridium botulinum in TYG broth and ground pork. J Food Prot. 1990 Nov;53(11):958-60.

28. Glass KA, Johnson EA. Antagonistic effect of fat on the antibotulinal activity of food preservatives and fatty acids. Food Microbiol. 2004 Dec;21(6):675-82.

29. Souza EL, Stamford TLM, Lima EO, Barbosa Filho JM, Marques MOM. Interference of heating on the antimicrobial activity and chemical composition of Origanum vulgare L. (Lamiaceae) essential oil. Ciência e Tecnol Aliment. 2008 Jun;28(2):418-22.

30. Aureli P, Costantini A, Zolea S. Antimicrobial activity of some plant essential oils against Listeria monocytogenes. J Food Prot. 1992 May;55(5):344-8. 